\title{
Decontamination of mycoplasma-contaminated Orientia tsutsugamushi strains by repeating passages through cell cultures with antibiotics
}

\author{
Motohiko Ogawa ${ }^{1 *}$, Tsuneo Uchiyama ${ }^{2}$, Masaaki Satoh ${ }^{1}$ and Shuji Ando ${ }^{1}$
}

\begin{abstract}
Background: Mycoplasmas-contamination of Orientia tsutsugamushi, one of the obligated intracellular bacteria, is a very serious problem in in vitro studies using cell cultures because mycoplasmas have significant influence on the results of scientific studies. Only a recommended decontamination method is to passage the contaminated O. tsutsugamushi strains through mice to eliminate only mycoplasmas under influence of their immunity. However, this method sometimes does not work especially for low virulent strains of $O$. tsutsugamushi which are difficult to propagate in mice. In this study, we tried to eliminate mycoplasmas contaminants from both high virulent and low virulent strains of the contaminated $O$. tsutsugamushi by repeating passage through cell cultures with antibiotics in vitro.

Results: We cultured a contaminated, high virulent strain of $O$. tsutsugamushi using a mouse lung fibroblasts cell line, L-929 cell in the culture medium containing lincomycin at various concentrations and repeated passages about every seven days. At the passage 5 only with $10 \mu \mathrm{g} / \mathrm{ml}$ of lincomycin, we did not detect mycoplasmas by two PCR based methods whereas $O$. tsutsugamushi continued good growth. During following four passages without lincomycin, mycoplasmas did not recover. These results suggested that mycoplasmas were completely eliminated from the high virulent strain of $O$. tsutsugamushi. Furthermore, by the same procedures with $10 \mu \mathrm{g} / \mathrm{ml}$ of lincomycin, we also eliminated mycoplasmas from a contaminated, low virulent strain of $O$. tsutsugamushi. Our additional assay showed that $50 \mu \mathrm{g} / \mathrm{ml}$ of lyncomycin did not inhibit the growth of O. tsutsugamushi, although MICs of many mycoplasmas contaminants were less than $6 \mu \mathrm{g} / \mathrm{ml}$ as shown previously.

Conclusion: Our results showed an alternative method to eliminate mycoplasmas from the contaminated $O$. tsutsugamushi strains in place of in vivo passage through mice. Especially this notable method works for the decontamination not only from the high virulent strain also from the low virulent strain of $O$. tsutsugamushi. For further elimination, lincomycin at the limit concentration, which does not inhibit the growth of $O$. tsutsugamushi, can possibly eliminate most mycoplasmas from contaminated O. tsutsugamushi strains.
\end{abstract}

Keywords: Orientia tsutsugamushi, Intracellular bacteria, Mycoplasma, Contamination, Elimination, Cell culture, Antibiotics

\section{Background}

The contamination of cell cultures by mycoplasmas is a serious problem because these bacteria have multiple effects on cell cultures and also have a significant influence on the results of scientific studies. The mycoplasmas are not harmless bystanders and thus cannot be ignored in the cell cultures.

\footnotetext{
* Correspondence: ogawam@nih.go.jp

'Department of Virology 1, National Institute of Infectious Diseases/1-23-1,

Toyama Shinjuku-ku, Tokyo 162-8640, Japan

Full list of author information is available at the end of the article
}

Various elimination methods were previously reported [1-3]. These methods are mainly based on four general procedures, physical, chemical, immunological and chemotherapeutic treatment. The physical procedures include heat treatment and filtration. The chemical procedures, treatments to detergents and other chemicals which are effective only against mycoplasmas, but not against host cells. The immunological procedures include in vitro co-culture with macrophages and specific anti-mycoplasmas antisera and in vivo passage thorough mice. The chemotherapeutic procedures are mainly antibiotics treatments that are kills mycoplasmas.

\section{Biomed Central}

(c) 2013 Ogawa et al.; licensee BioMed Central Ltd. This is an Open Access article distributed under the terms of the Creative Commons Attribution License (http://creativecommons.org/licenses/by/2.0), which permits unrestricted use, distribution, and reproduction in any medium, provided the original work is properly cited. 
Orientia tsutsugamushi, which is the causative agents of scrub typhus is one of the obligated intracellular bacteria [4]. The mycoplasmas-contaminations of O. tsutsugamushi is also very serious in the in vitro studies using cell cultures. Furthermore the most effective methods for elimination of mycoplasmas can not be applied for decontamination of $O$. tsutsugamushi strains because these methods also inhibit the growth of O. tsutsugamushi. Decontamination methods should have strong effect on mycoplasmas, but have minimum or no effect on O. tsutsugamushi. Only the recommended decontamination method is to passage the contaminated O. tsutsugamushi strains through mice. Mouse immunity possibly eliminates only mycoplasmas, although O. tsutsugamushi can survive in its target cells, mainly endothelial cells, splenocytes and hepatocytes. In fact, homogenized spleen of infected mice is generally used for the next inoculation. However, this method sometimes does not work especially for low virulent strains of O. tsutsugamushi because they are generally difficult to propagate in mice.

Some of the antibiotics, which are used for elimination of mycoplasmas from tissue culture, are supposed to have less effect against O. tsutsugamushi according to the differences of minimum inhibitory concentrations (MICs) of antibiotics between mycoplasmas [5-7] and $O$. tsutsugamushi [8]. In this study, we tried to eliminate mycoplasmas from contaminated O. tsutsugamushi strains by repeating passages through cell cultures with antibiotics in vitro.

\section{Results and discussion}

According to the MICs of antibiotics in the previous reports [5,7-9], we used two antibiotics, lincomycin and ciprofloxacin for elimination of mycoplasmas from the contaminated O.tsutsugamushi strains (Table 1). Both lincomycin and ciprofloxacin are effective against mycoplasmas. Unfortunately there is no available information about the MICs of lincomycin against O. tsutsugamushi. However, according to the MICs of lincomycin against gram-negative bacteria [10], lincomycin is supposed to be much less effective against $O$. tsutsugamushi because

Table 1 Minimum inhibitory concentrations (MICs) of antibiotics used in this study

\begin{tabular}{|c|c|c|c|}
\hline Antibiotics & Drug class & MICs against Orientia ${ }^{\text {a) }}$ & $\begin{array}{l}\text { MICs against } \\
\text { mycoplasmas }^{\text {b) }}\end{array}$ \\
\hline Lincomycin & Lincosamide & No available data & $0.25-2 \mu \mathrm{g} / \mathrm{mL}$ \\
\hline Ciprofloxacin & New Quinolone & $6.25-25 \mu \mathrm{g} / \mathrm{mL}$ & $0.125-2 \mu \mathrm{g} / \mathrm{ml}$ \\
\hline Gentamicin & Aminoglycoside & No available data ${ }^{\text {c) }}$ & $2.5-500 \mu \mathrm{g} / \mathrm{mL}$ \\
\hline Kanamicin & Aminoglycoside & No available data & $2.5-500 \mu \mathrm{g} / \mathrm{mL}$ \\
\hline Minocycline & Tetracycline & $0.024-0.195 \mu \mathrm{g} / \mathrm{mL}$ & $0.016-32 \mu \mathrm{g} / \mathrm{mL}$ \\
\hline
\end{tabular}

MICs were obtained from previous reports. a) from [8] and b) from [5-7]. c) Gentamycin was not effective against Orinetia tsutsugamushi in a mouse model [25].
O. tsutsugamushi is one of the gram-negative bacteria. For the example, the MICs of lincomycin against Escherichia coli, one of the typical gram gram-negative bacteria are more than 50 times higher than those against mycoplasmas. Ciprofloxacin was also less effective against $O$. tsutsugamushi. The MICs of ciprofloxacin against $O$. tsutsugamushi are about 3 to 200 times higher than those against mycoplasmas (Table 1).

Our result of the direct sequencing showed that Ikeda and Kuroki strains of O. tsutsugamushi were contaminated with Mycoplasma hominis and $M$. orale respectively. M. hominis and $M$. orale are 10 to $30 \%$ of contaminants of cell cultures (Table 2) [11]. Previous reports showed that $M$. fermentas, M. hyorhinis, M. arginini and Acholeplasma laidlawii are the most common contaminants as well as $M$. hominis and $M$. orale. More than $90 \%$ of the contaminants were caused by these six mycoplasmas $[11,12]$. The TaqMan PCR and the nested PCR can detect not only all the 6 most common contaminants also some other mycoplasmas. These facts suggested that the detection methods were very reliable to monitor mycoplasmas-contaminations in this study.

For elimination of mycoplasmas, we first cultured a contaminated, high virulent Ikeda strain of O. tsutsugamushi using L-929 cell in the culture medium containing lincomycin and ciprofloxacin and repeated the passages (Figure 1). Lincomycin and ciprofloxacin were used at 100,10 and $1 \mu \mathrm{g} / \mathrm{ml}$. However, ciprofloxacin at $100 \mu \mathrm{g} / \mathrm{ml}$ were cytotoxic against L-929 cell in the first assay and was omitted from the further analyses. We checked mycoplasma-contaminations and O. tsutsugamushi-growth at each passage by the two PCR based methods and/or an immunofluorescent (IF) staining (see Additional file 1). From the passage 1 to 2 with $10 \mu \mathrm{g} / \mathrm{ml}$ of lincomycin, the real-time PCR showed that mycoplasmas decreased, whereas $O$. tsutsugamushi did not decrease. At the passage 4 with the same concentration of lincomycin, the realtime PCR did not detect mycoplasmas, however the nested PCR still detected them. At the passage 5, both the real-time PCR and the nested PCR did not detect mycoplasmas, whereas the flourish growth of O. tsutsugamush $i$ was observed by IF staining. We continued to culture with lincomycin until the passage 6. During following passages from 7 to 10 without lincomycin, mycoplasmas did not recover. These results clearly showed that mycoplasmas were completely eliminated from O. tsutsugamushiinfected cells. However, the cultivation with $100 \mu \mathrm{g} / \mathrm{ml}$ of lincomycin as well as 10 and $1 \mu \mathrm{g} / \mathrm{ml}$ of ciprofloxacin decreased both mycoplasmas and O. tsutsugamushigrowths, whereas the cultivation with $1 \mu \mathrm{g} / \mathrm{ml}$ of lincomycin did not influence the neither growths.

By the same procedure of Ikeda strain, we cultured a contaminated, low virulent Kuroki strain of O. tsutsugamushi with lincomycin at $10 \mu \mathrm{g} / \mathrm{ml}$ (Figure 1). Mycoplasmas and 
Table 2 Major mycoplasmas, and their detection and sequencing methods in this study

\begin{tabular}{|c|c|c|c|c|c|c|}
\hline \multirow[t]{2}{*}{ Species } & \multirow[b]{2}{*}{$\begin{array}{l}\text { Frequency of } \\
\text { contamination }^{\text {a) }}\end{array}$} & \multicolumn{2}{|l|}{ PCR for detection } & \multirow{2}{*}{$\begin{array}{l}\text { PCR for } \\
\text { Sequencing } \\
\text { Match of new } \\
\text { PCR primers }\end{array}$} & \multirow[b]{2}{*}{ Strains } & \multirow[b]{2}{*}{ Sequence ID } \\
\hline & & $\begin{array}{l}\text { tuf gene } \\
\left(_{\text {TaqMan PCR) }}^{\text {b) }}\right.\end{array}$ & $\begin{array}{l}\text { 16S-23S ribosomal } \\
\text { RNA intergenic } \\
\text { region (nested PCR) }\end{array}$ & & & \\
\hline \multicolumn{7}{|c|}{ Most common contaminant species } \\
\hline Mycoplasma fermentans & $10 \%-20 \%$ & + & + & Match & $\begin{array}{l}\text { human B cell } \\
\text { lymphoma } \\
\text { contaminants, } \\
16054780\end{array}$ & AY838558 \\
\hline Mycoplasma hyorhinis & $10 \%-40 \%$ & + & + & Match & HUB-1 & NC_014448.1 \\
\hline Mycoplasma orale & $20 \%-30 \%$ & + & + & Partial Match & ATCC 23714D & gi|315440428 \\
\hline Mycoplasma arginini & $20 \%-30 \%$ & No Data & + & Partial Match & G230 & gi|290575476 \\
\hline Acholeplasma laidlawii & $5 \%-20 \%$ & + & + & Match & PG-8A & CP000896 \\
\hline Mycoplasma hominis & $10 \%-20 \%$ & + & + & Match & ATCC 23114 & M57675 \\
\hline \multicolumn{7}{|l|}{ Other species } \\
\hline Mycoplasma arthritidis & No Data & + & No Data & Match & 158L3-1 & NC_011025.1 \\
\hline Mycoplasma bovis & No Data & + & No Data & Match & PG45 & NC_014760.1 \\
\hline Mycoplasma buccale & No Data & + & No Data & No data & - & - \\
\hline Mycoplasma faucium & No Data & + & No Data & No data & - & - \\
\hline Mycoplasma gallisepticum & No Data & + & No Data & Match & PG31 & X16462 \\
\hline Mycoplasma genitalium & No Data & + & + & Match & ATCC33530 & $\times 16463$ \\
\hline Mycoplasma hyopneumoniae & No Data & + & No Data & Match & 7448 & NC_007332.1 \\
\hline Mycoplasma penetrans & No Data & + & No Data & Match & $\mathrm{HF}-2$ & NC_004432.1 \\
\hline Mycoplasma pneumoniae & No Data & + & + & Match & $\mathrm{FH}$ & $\times 55768$ \\
\hline Mycoplasma primatum & No Data & + & No Data & No data & - & - \\
\hline Mycoplasma salivarium & No Data & + & + & Partial Match & ATCC 23064D & gi|313575713 \\
\hline Ureaplasma parvum & No Data & + & No Data & Match & ATCC 33697 & AF270770 \\
\hline Mycoplasma zalophi & No Data & No Data & No Data & Match & CSL 4296 & gi|148536300 \\
\hline Mycoplasma mycoides & No Data & No Data & No Data & Match & PG1 & gi|126252003 \\
\hline Mycoplasma capricolum & No Data & No Data & No Data & Match & ATCC 27343 & gi|83319253 \\
\hline Mycoplasma agalactiae & No Data & No Data & No Data & Match & PG2 & gi|148291314 \\
\hline Mycoplasma pyrum & No Data & No Data & + & No data & - & - \\
\hline
\end{tabular}

a) Upper 6 species of mycoplasmas are the most common contaminants of cell cultures [11,12].

b) This broad-range TaqMan PCR can detect many species of mycoplasmas [22].

c) This nested PCR is highly sensitive, and it is used to check for mycoplasma contamination in the Cell Bank of BioResource Centre, Riken Tsukuba Institute, Tsukuba, Ibaraki, Japan [21].

d) PCR assay for sequencing of mycoplasmas designed in this study. Partial Match means that 2 or 3 of the total of 4 nested-PCR primers match to available regions of the tuf gene on the public database.

O. tsutsugamushi were monitored by the nested PCR and the IF assay respectively (see Additional file 2). At the passage 8 , the nested PCR did not detect mycoplasmas. We then continued to cultivate it with lincomycin until the passage 11. During following passages from 12 to 14 without lincomycin, mycoplasmas did not recover. These results showed that we successfully eliminated mycoplasmas also from the low virulent Kuroki strain. The elimination length of Kuroki strain was longer than that of Ikeda strain probably because numbers and/or antibioticssusceptibility of the contaminated mycoplasmas were different. For further elimination of mycoplasmas from other strains of $O$. tsutsugamushi, we should first evaluate a maximum concentration of lincomycin that does not influence O. tsutsugamushi-growth, and then apply it for decontamination because maximum effects against mycoplasmas are necessary to eliminate them for a short time and to avoid producing lincomycin-resistant mycoplasmas [13-15] during repeating passages. Our additional assay showed that lincomycin at $25 \mu \mathrm{g} / \mathrm{ml}$ did not affect the growth (the virulent strain), whereas $50 \mu \mathrm{g} / \mathrm{ml}$ slightly decreased (did not inhibit) the growth in the IF assay (Table 3). Many previous reports about antibioticssusceptibilities of isolated mycoplasmas showed that MICs of lyncomycin against $M$. hominis, $M$. fermentas and $A$. laidlawii, which are the major contaminants, were less 


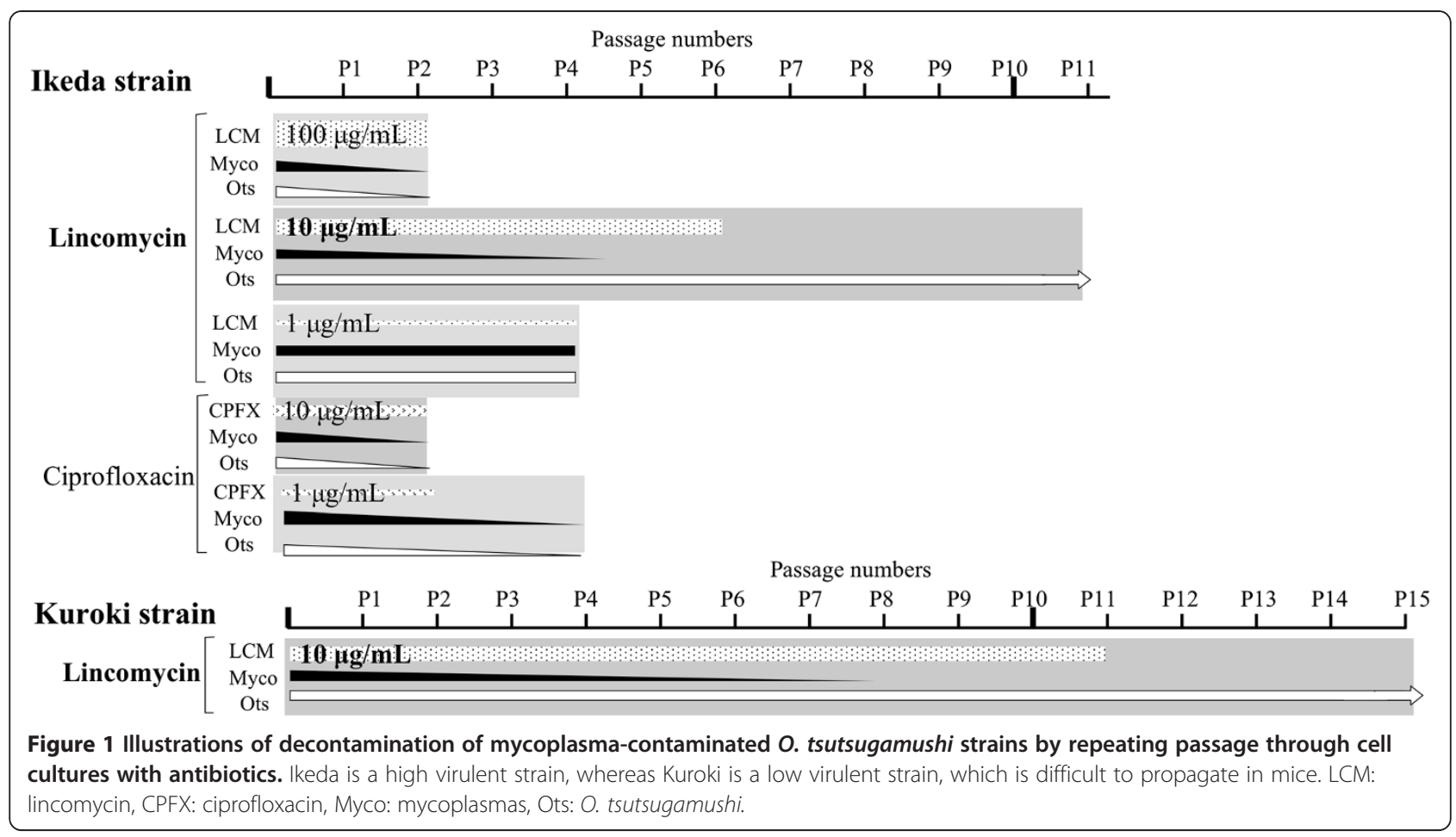

than $6 \mu \mathrm{g} / \mathrm{ml}(0.025$ to $6 \mu \mathrm{g} / \mathrm{ml})$ [5,16-18]. In actual, a previous report showed that lincomycin at $50 \mu \mathrm{g} / \mathrm{ml}$ successfully eliminated the other major contaminants of mycoplasmas, $M$. hyorhinis and $M$. hominis from cell cultures [19]. However, a previous report showed that some isolates of $M$. hyorhinis were highly resistant to lyncomycin (MICs > $100 \mu \mathrm{g} / \mathrm{ml}$ ) [14] and a few reports showed that other species of mycoplasmas but not major species of contaminants were highly resistant to lyncomycin $[13,15]$. Considering these facts, lincomycin at $50 \mu \mathrm{g} / \mathrm{ml}$ can possibly eliminate the contaminants from many of other contaminated strains of O. tsutsugamushi, although it might not be effective for all the cases.

\section{Conclusions}

Our results showed an alternative method to eliminate mycoplasmas from the mycoplasma-contaminated

Table 3 The growth of 0 . tsutsugamushi at the various concentrations of lincomycin

\begin{tabular}{lllll}
\hline & \multicolumn{3}{l}{$\begin{array}{l}\text { Concentrations of lincomycin in the culture } \\
\text { medium }\end{array}$} \\
\hline $12.5 \mu \mathrm{g} / \mathrm{ml}$ & $25 \mu \mathrm{g} / \mathrm{ml}$ & $50 \mu \mathrm{g} / \mathrm{ml}$ & $100 \mu \mathrm{g} / \mathrm{ml}$ \\
O. tsutsugamsuhi-growth $^{\text {a) }}$ & +++ & +++ & ++ & - \\
\hline
\end{tabular}

a) A virulent lkeda strain was cultivated using L-929 cell in the culture medium containing lyncomycin at the indicated concentrations. The growth was observed by the immunofluorescent staining. strains of $O$. tsutsugamushi in place of in vivo passage through mice. Especially this new method works for the decontamination not only from the high virulent strain also from the low virulent strain of O. tsutsugamushi, which is difficult to propagate in mice. For further elimination, lincomycin at the limit concentration, which does not inhibit the growth of O. tsutsugamushi, can possibly eliminate most mycoplasmas from contaminated $O$. tsutsugamushi strains.

\section{Methods}

\section{Cell lines}

A mycoplasmas-free L-929 cell (a mouse fibroblast cell line, JCRB9003) [20] was grown in Eagle's minimum essential medium (MEM, Wako Co. Ltd., Tokyo, Japan) supplemented with 5 to $10 \%$ of mycoplasma-free, heatinactivated FCS (Sigma-Aldrich Japan Co. LCC., Tokyo, Japan) at $37^{\circ} \mathrm{C}$ in $5 \% \mathrm{CO}_{2}$.

\section{Mycoplasmas-contaminated $O$. tsutsugamushi strains for elimination}

A mycoplasmas-contaminated high virulent Ikeda strain and a low virulent Kuroki strain of O. tsutsugamushi were used for elimination. These strains were accidentally contaminated during a long passage history probably because mycoplasmas-contaminated cell culture was used for propagation of these strains. The mycoplasmafree L-929 cell was used for propagation as mentioned in the previous section. 


\section{Detection and quantification of mycoplasmas}

Major mycoplasmas are listed in Table 2. Upper 6 species are the most common contaminants in cell cultures $[11,12]$. In order to monitor mycoplasmas, we extracted DNA from O. tsutsugamushi-infected L-929 cell with a commercial DNA extract kit (Tissue genomic DNA extraction mini kit, Favorgen biotech corporation, Ping-Tung, Taiwan) and detected mycoplasmas by two high sensitive and broad range PCR based methods for detection, the nested PCR [21] and the real-time PCR (TaqMan PCR) [22]. The nested PCR is used to check mycoplasma-contaminations in the Cell Bank of Bioresource Centre, Riken Tsukuba institute, Tsukuba, Ibaraki, Japan. For determination of mycoplasma species, we designed new sequencing primers against tuf gene (Table 2). These designed primers matched tuf gene of 19 mycoplasmas on the public database. All the primers and the probe are listed in Table 4.

\section{Detection of $O$. tsutsugamushi}

To monitor the growth of O. tsutsugamushi, we used a real-time PCR against the gene encoding $47 \mathrm{kDa}$ common antigen (Table 4). We extracted DNA from O. tsutsugamushi-infected L-929 cell as mentioned in the previous section and performed the real-time PCR according to the general procedure [23]. We also used an IF staining to monitor the growth of O. tsutsugamushi. In this staining, human convalescent sera of a scrub typhus patient, which were permitted by the ethics committee (number 255), and anti-human antibody conjugated with AlexaFluor ${ }^{\circledR} 488$ (Life technologies Japan Ltd, Tokyo, Japan) were used. A part of the infected cells were harvested and fixed on a glass slide with ice cold acetone and then the slide was applied for the IF staining according to the previous reports [24].

\section{Antibiotics}

Lincomycin (Wako Pure Chemical Industries, Ltd., Osaka, Japan) and ciprofloxacin (Wako Pure Chemical Industries, Ltd., Osaka, Japan) were used for elimination of mycoplasmas in this study. Kanamycin and gentamycin are routinely used for propagation of O. tsutsugamushi to avoid accidental bacterial contamination in our laboratory because they do not influence O. tsutsugamushi-growth [25].

\section{Elimination of mycoplasmas from 0 . tsutsugamushi- infected cells with antibiotics}

We cultured the contaminated strains of $O$. tsutsugamushi using L-929 cell in the culture medium containing lincomycin and ciprofloxacin at 100,10 and $1 \mu \mathrm{g} / \mathrm{ml}$ in $25 \mathrm{~cm} 2$ tissue culture flask, and repeated passages about every seven days. At each passage, the infected cells were harvested. One-third of the harvested cells was used for the next inoculation, another one-third was used for DNA extraction, and the remaining one-third was frozen and stocked. Elimination of mycoplasmas was checked by the nested PCR and/or real-time PCR. The growth of O. tsutsugamushi was monitored by the real-time PCR and/or the IF staining.

Table 4 Primers and probes for detection and sequencing in this study

\begin{tabular}{|c|c|c|c|}
\hline Targets & Assay & Name & Primers and probes \\
\hline \multicolumn{4}{|l|}{ Mycoplasmas } \\
\hline \multirow[t]{3}{*}{ tuf gene ${ }^{a)}$} & real-time PCR & Mollicutes 414F & 5'-TCCAGGWCAYGCTGACTA-3' \\
\hline & & Mollicutes 541R & 5'-ATTITWGGAACKCCWACTTG-3' \\
\hline & & Probe $451 \mathrm{~F}^{\mathrm{a})}$ & 5'-GGTGCTGCACAAATGGATGGG-3' \\
\hline \multirow[t]{4}{*}{ tuf gene } & Sequencing 1st & Myco-tuf-F1 & 5'-HATHGGCCAYRTTGAYCAYGGKAAAA-3' \\
\hline & & Myco-tuf-F2 & 5'-ATGATYACHGGDGCWGCHCAAATGGA-3' \\
\hline & Sequencing 2nd & Myco-tuf-R1 & 5'-CCRCCTTCRCGRATDGAGAAYTT-3' \\
\hline & & Myco-tuf-R2 & 5'-TKTRTGACGDCCACCTTCYTC-3' \\
\hline \multirow[t]{4}{*}{ 16s-23s rRNA intergenic spacer region } & nested PCR 1st & MCGpF11 & 5'-ACACCATGGGAGYTGGTAAT-3' \\
\hline & & R23-1R & 5'-CTCCTAGTGCCAAGSCATYC-3' \\
\hline & nested PCR 2nd & R16-2 & 5'-GTGSGGMTGGATCACCTCCT-3' \\
\hline & & MCGpR21 & 5'-GCATCCACCAWAWACYCTT-3' \\
\hline \multicolumn{4}{|l|}{ Orientia tsutsugamushi } \\
\hline \multirow[t]{3}{*}{ 47kDa common antigen coding gene } & real-time PCR & Ots-47k-F & 5'-AATTCGTCGTGGTATGTTAAATG-3' \\
\hline & & Ots-47k-R & 5'-AGCAATTCCACATTGTGCTG-3' \\
\hline & & Ots-47k-P b) & 5'-TGCTTAATGAATTAACTCCAGAATT-3' \\
\hline
\end{tabular}

a) Locked nucleic acid (LNA) bases (underlined) and was synthesized with the fluorescent reporter 6-carboxyfluorescein (FAM) covalently coupled to the $5^{\prime}$ end and a dark quencher to the $3^{\prime}$ end.

b) TaqMan probe was synthesized with the fluorescent reporter 6-carboxyfluorescein (FAM) covalently coupled to the $5^{\prime}$ end and a dark quencher to the $3^{\prime}$ end. 


\section{Additional files}

Additional file 1: Decontamination of a mycoplasma-contaminated, high-virulent strain of Orientia tsutsugamushi (Ikeda strain) by repeated passages with antibiotics.

Additional file 2: Decontamination of a mycoplasma-contaminated, low-virulent strain of Orientia tsutsugamushi (Kuroki strain).

\section{Competing interests}

All authors declare that they have no competing interest.

\section{Authors' contribution}

MO carried out the entire part of this study. TU carried out DNA sequences and some genetic analyses of mycoplasmas. MS and SA helped the passages of O. tsutsugamushi in cell culture with lyncomycin and checked mycoplasmas and O.tsutsugamushi by PCR and IF assay. All authors read and approved the final manuscript.

\section{Acknowledgements}

This study was financially supported by a grant from the Ministry of Health, Labour and Welfare, Japan (number H21-Shinkou-Ippan-006 and H23-

Shinkou-Ippan-007 from 2010 to 2012)

\section{Author details}

1Department of Virology 1, National Institute of Infectious Diseases/1-23-1, Toyama Shinjuku-ku, Tokyo 162-8640, Japan. ${ }^{2}$ Institute of Health Biosciences, The University of Tokushima Graduate School/3-18-15, Kuramoto-cho, Tokushima 770-8503, Japan.

Received: 2 August 2012 Accepted: 17 January 2013

Published: 8 February 2013

\section{References}

1. Uphoff CC, Drexler HG: Eradication of mycoplasma contaminations. Methods Mol Biol 2005, 290:25-34.

2. Uphoff CC, Drexler HG: Elimination of mycoplasmas from infected cell lines using antibiotics. Methods Mol Biol 2011, 731:105-114.

3. Uphoff CC, Meyer C, Drexler HG: Elimination of mycoplasma from leukemialymphoma cell lines using antibiotics. Leukemia 2002, 16(2):284-288.

4. Tamura A, Ohashi N, Urakami H, Miyamura S: Classification of Rickettsia tsutsugamushi in a new genus, Orientia gen. nov., as Orientia tsutsugamushi comb. nov. Int J Syst Bacteriol 1995, 45(3):589-591.

5. Hannan PC: Antibiotic susceptibility of Mycoplasma fermentans strains from various sources and the development of resistance to aminoglycosides in vitro. J Med Microbiol 1995, 42(6):421-428.

6. Waites KB, Duffy LB, Schmid T, Crabb D, Pate MS, Cassell GH: In vitro susceptibilities of Mycoplasma pneumoniae, Mycoplasma hominis, and Ureaplasma urealyticum to sparfloxacin and PD 127391. Antimicrob Agents Chemother 1991, 35(6):1181-1185.

7. Wu CC, Shryock TR, Lin TL, Faderan M, Veenhuizen MF: Antimicrobial susceptibility of Mycoplasma hyorhinis. Vet Microbiol 2000, 76(1):25-30.

8. Miyamura S, Ohta T, Tamura A: Comparison of in vitro susceptibilities of Rickettsia prowazekii, R. rickettsii, $R$. sibirica and $R$. tsutsugamushi to antimicrobial agents. Nihon Saikingaku Zasshi 1989, 44(5):717-721.

9. Rolain JM, Maurin M, Vestris G, Raoult D: In vitro susceptibilities of 27 rickettsiae to 13 antimicrobials. Antimicrob Agents Chemother 1998, 42(7):1537-1541.

10. Ohno R: Antibiotic-books. [http://www.antibiotic-books.jp].

11. Manilof J, McElhaney RN, Finch LR, Baseman JB: Mycoplasmas: molecular biology and pathogenesis. Washington D.C: American Society for Mycrobiology; 1992.

12. Drexler HG, Uphoff CC: Mycoplasma contamination of cell cultures: Incidence, sources, effects, detection, elimination, prevention. Cytotechnology 2002, 39(2):75-90.

13. Nitu Y, Hasegawa S, Kubota H: In vitro development of resistance to erythromycin, other macrolide antibiotics, and lincomycin in Mycoplasma pneumoniae. Antimicrob Agents Chemother 1974, 5(5):513-519.

14. Kobayashi H, Nakajima H, Shimizu Y, Equchi M, Hata E, Yamamoto K. Macrolides and lincomycin susceptibility of Mycoplasma hyorhinis and variable mutation of domain II and V in 23S ribosomal RNA. J Vet Med Sci 2005, 67(8):795-800
15. Stopler T, Branski D: Resistance of Mycoplasma pneumoniae to macrolides, lincomycin and streptogramin B. J Antimicrob Chemother 1986, 18(3):359-364.

16. Aarestrup FM, Friis NF: Antimicrobial susceptibility testing of Mycoplasma hyosynoviae isolated from pigs during 1968 to 1971 and during 1995 and 1996. Vet Microbio/ 1998, 61(1-2):33-39.

17. Harwick HJ, Fekety FR Jr: The antibiotic susceptibility of Mycoplasma hominis. J Clin Pathol 1969, 22(4):483-485.

18. Uemura R, Sueyoshi M, Nagatomo H: Antimicrobial susceptibilities of four species of Mycoplasma isolated in 2008 and 2009 from cattle in Japan. J Vet Med Sci 2010, 72(12):1661-1663.

19. Hirschberg L, Bolske G, Holme T: Elimination of mycoplasmas from mouse myeloma cells by intraperitoneal passage in mice and by antibiotic treatment. Hybridoma 1989, 8(2):249-257.

20. Earle WR: Production of malignancy in vitro.The mouse fibroblast cultures and changes seen in the living cells. J National Cancer Res Inst 1943, 4:165-212.

21. Harasawa R, Mizusawa H, Nozawa K, Nakagawa T, Asada K, Kato I: Detection and tentative identification of dominant mycoplasma species in cell cultures by restriction analysis of the 16S-23S rRNA intergenic spacer regions. Res Microbiol 1993, 144(6):489-493.

22. Stormer M, Vollmer T, Henrich B, Kleesiek K, Dreier J: Broad-range real-time PCR assay for the rapid identification of cell-line contaminants and clinically important mollicute species. Int J Med Microbiol 2009, 299(4):291-300.

23. Hanaoka N, Matsutani M, Kawabata H, Yamamoto S, Fujita H, Sakata A, Azuma Y, Ogawa M, Takano A, Watanabe H, et al: Diagnostic assay for Rickettsia japonica. Emerg Infect Dis 2009, 15(12):1994-1997.

24. Ogawa M, Matsumoto K, Parola P, Raoult D, Brouqui P: Expression of rOmpA and rOmpB protein in Rickettsia massiliae during the Rhipicephalus turanicus life cycle. Ann N Y Acad Sci 2006, 1078:352-356

25. McClain JB, Joshi B, Rice R: Chloramphenicol, gentamicin, and ciprofloxacin against murine scrub typhus. Antimicrob Agents Chemother $1988,32(2) \cdot 285-286$

doi:10.1186/1471-2180-13-32

Cite this article as: Ogawa et al.: Decontamination of mycoplasmacontaminated Orientia tsutsugamushi strains by repeating passages through cell cultures with antibiotics. BMC Microbiology 2013 13:32.

\section{Submit your next manuscript to BioMed Central and take full advantage of:}

- Convenient online submission

- Thorough peer review

- No space constraints or color figure charges

- Immediate publication on acceptance

- Inclusion in PubMed, CAS, Scopus and Google Scholar

- Research which is freely available for redistribution

Submit your manuscript at www.biomedcentral.com/submit
C BioMed Central 